\title{
Struktur morfologi jenis makro alga di perairan Siko Kepulauan Gura Ici Kabupaten Halmahera Selatan Provinsi Maluku Utara
}

(Morphology structure of macro algae type in Siko Gura Ici archipelago waters of South Halmahera Regency, North Mollucas Province)

\author{
Iwan Hi. Kader ${ }^{1}$, Grevo S. Gerung ${ }^{2}$ \\ ${ }^{1}$ Program Studi Manajemen Sumberdaya Perairan, Fakultas Perikanan dan Kelautan \\ Universitas Khairun Ternate. \\ ${ }^{2}$ Program Studi Ilmu Kelautan, Fakultas Perikanan dan Ilmu Kelautan Universitas \\ Samratulangi Manado. \\ e-mail: iwan.kader19@gmail.com
}

Diterima: 20 Maret 2020; Disetujui: 11 November 2020

\begin{abstract}
ABSTRAK
Penelitian ini dilaksanakan di perairan Siko Kepulauan Gura Ici Kabupaten Halmahera Selatan, Provinsi Maluku Utara pada bulan Pebruari 2005. Tujuan penelitian ini untuk melihat struktur morfologi dan komposisi jenis makro alga. Pengambilan sampel makro alga dilakukan dengan menggunakan metode garis transek (line Transect) di satu stasiun yang telah ditentukan. Pengambilan sampel jenis makro alga dilakukan secara acak pada transek yang telah di plot seluas 100 x 100 meter. Analisis data menggunakan analisis deskriptif. Hasil penelitian teridentifikasi sebanyak 19 jenis yang dibagi dalam tiga divisi, yaitu chlorophyta sebanyak 9 jenis, rhodophyta sebanyak 7 jenis dan phaeophyta sebanyak 3 jenis. Pengukuran morfologi dari jenis makro alga terlihat bahwa diameter batang (thallus) tergolong cukup besar dari ukuran normalnya.
\end{abstract}

Kata kunci: Makro alga, Morfologi, Gura Ici.

\section{ABSTRACT}

This research was conducted in Siko Gura Ici Islands, South Halmahera Regency, North Moluccas Province in February 2005. The purpose of this study was to look at the morphological structure and composition of macro algae species. Makro algae sampling was carried out using the transect line method at a predetermined station. Sampling of macro algae is carried out random on transects that have been plotted along $100 \times 100$ meters. Date analysis uses descriptive analysis. The results of the study were identified as many 19 types which were divided into three divisions, namely 9 types of chlorophyta, 7 types of rhodophyta and 3 types of phaeophyta. Morphological measurements of the macro type indicate that the diameter of the stem (thallus) is quite large than its normal size.

Keywords: Macro algae, Morphology, Gura Ici. 


\section{Pendahuluan}

Potensi sumberdaya perikanan dan kelautan memiliki prospek yang sangat cerah untuk dibangun menjadi suatu kekuatan ekonomi yang tangguh, strategis dan berkelanjutan. Alga merupakan salah satu dari berbagai sumberdaya perairan tropis dan merupakan bagian yang terbesar dari tumbuhan laut. Alga laut dapat dibedakan berdasarkan ukurannya, alga dibagi menjadi dua yaitu alga mikro yang cara hidupnya bisa sebagai fitoplankton (alga planktonik) yang mengapung atau melayang-layang di dalam air, serta alga makro (alga bentik) yang hidupnya menancap atau melekatkan akar di dasar perairan. Alga laut dapat dijumpai hidup dan melekat pada berbagai tipe substrat seperti, substrat berpasir, berlumpur, dan bahkan pada tipe substrat keras seperti karang dan batu. Alga hidup dengan menancapkan dirinya pada substrat berlumpur, pasir, karang, karang mati, kulit kerang, batu kayu dan bahkan pula hidup sebagai epifit dengan menancapkan dirinya pada tumbuhan lain (Trono, 1997). Gerung (2001a), menyatakan bahwa pada dasarnya ada tiga cara alga terdistribusi yaitu, melalui arus, melalui sarana transportasi laut serta dengan sengaja diintroduksi oleh manusia.

Dari segi morfologi, alga berbeda dengan tumbuh-tumbuhan lain yang ada di daratan. Berdasarkan pigmen yang dikandungnya, umumnya alga dapat dibagi dalam beberapa divisi yaitu, alga biru hijau (Cyanophyceae), alga hijau (Chlorophyceae), alga coklat (Phaeophyceae) dan alga merah (Rhodophyceae). Secara morfologi jenis alga tidak dapat dibedakan antara akar, batang dan daun, sehingga tumbuhan ini dikelompokkan ke dalam tumbuhan Thallophyta. Thallophyta adalah tumbuhan dengan kerangka tubuh yang tak berdaun, berbatang dan berakar, tetapi semuanya terdiri dari batang thallus yang bermacam bentuknya, ada yang berbentuk seperti tabung, bulat, pipih, gepeng, kantung, rambut dan sebagainya (Trainor, 1978).

Sumich (1992) menggambarkan bahwa struktur alga terdiri dari tiga struktur bagian yaitu struktur yang menyerupai daun utama yang dikenal dengan blade yaitu bagian yang menyerupai daun pipih yang biasanya lebar, kemudian kedua adalah stipe yaitu bagian yang menyerupai batang dan berfungsi sebagai penahan goncangan ombak, dan ketiga yaitu holdfast yang merupakan bagian yang menyerupai akar yang berfungsi sebagagi alat pelekat pada substrat.

Kepulauan Guraici berada di garis khatulistiwa memiliki sumberdaya laut yang melimpah seperti ikan, teripang, moluska, terumbu karang, padang lamun dan mangrove serta terdapat pula alga laut yang belum terjamah dan belum termanfaatkan dengan baik, terutama dalam hal pengkajian serta penelitian secara ilmiah guna mendapatkan suatu informasi untuk pengembangan sumberdaya ini. Tujuan penelitian ini yaitu untuk mengetahui komposisi jenis makro alga melalui pendekatan struktur morfologi di stasiun penelitian pulau Siko kepulauan Gura Ici.

\section{Metode Penelitian}

\section{II.1. Waktu dan tempat penelitian}

Penelitian ini dilakukan di perairan Pulau Siko Kepulauan Gura Ici Kabupaten Halmahera Selatan, Provinsi Maluku Utara pada bulan Pebruari 2005. Lokasi Penelitian dapat dilihat pada Gambar 1. 


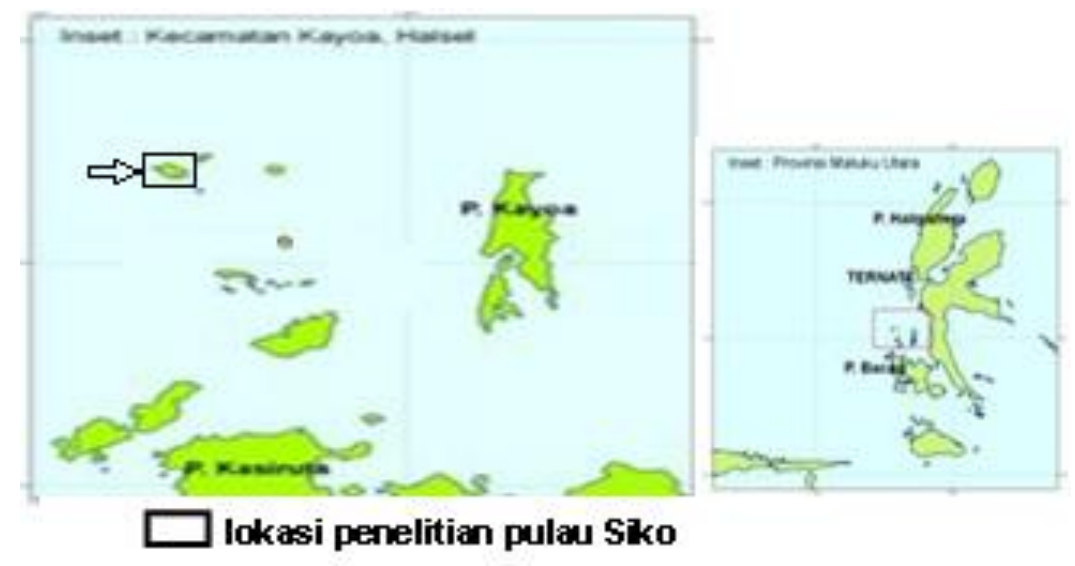

\section{II.2. Metode pengambilan sampel}

Pengambilan sampel dilakukan pada saat air surut (pasang terendah) agar sampel alga dapat terlihat dengan jelas serta dengan mudah untuk dikumpulkan. Metode pengambilan sampel yaitu dengan menggunakan metode garis transek (line transect) dengan penempatan tali transek yang diplot seluas 100 x 100 meter. Pengambilan sampel jenis makro alga dilakukan secara acak dengan cara mengambil sampel makro alga dan dimasukkan kedalam cool box yang telah disiapkan. Selanjutnya jenis makro alga yang telah terkumpul dilakukan identifikasi dengan menggunakan buku identifikasi Calumpong dan Menez (1997). Setelah seluruh spesimen teridentifikasi, dari spesimenspesimen tersebut dilakukan pengukuran untuk mengetahui struktur morfologi dengan menggunakan mistar dan vernier caliper dengan ketelitian $0,02 \mathrm{~mm}$ seperti panjang, tinggi, diameter stolon dan thallus (batang), jumlah segmen, ramuli (buah), lebar daun serta tinggi thallus dari jenis makro alga yang ditemukan. Pengukuran parameter perairan dilakukan secara in-situ bersamaan dengan pengambilan sampel makro alga, meliputi suhu permukaan air laut dengan menggunakan termometer celup berketelitian $1^{\circ} \mathrm{C}$, Salinometer celup berketilitian $1 \%$ digunakan untuk mengukur salinitas permukaan air laut. Selain itu substrat dasar perairan dilakukan dengan pengamatan secara visual di lapangan dan dicatat kondisi substratnya.

\section{Hasil dan Pembahasan}

\section{III.2. Parameter lingkungan}

Substrat yang mendominasi lokasi penelitian yaitu substrat berpasir, pasir berlumpur dan patahan karang mati. Sementara hasil pengukuran suhu permukaan air laut yaitu $32^{\circ} \mathrm{C}$, Sedangkan salinitas air laut yang terukur pada stasiun penelitian yaitu $33 \%$. Kisaran salinitas tersebut merupakan salinitas yang cocok untuk kehidupan dan pertumbuhan alga. Setiap spesies alga memiliki toleransi salinitas tertentu untuk dapat hidup dan bertumbuh secara maksimal (Luning 1994). Sementara Lobban dan Harrison (1994) megemukakan bahwa suhu suatu perairan berpengaruh besar terhadap struktur dan molekuler alga laut.

\section{III.2.Komposisi spesies makro alga}

Komposisi spesies makro alga yang ditemukan dilokasi penelitian sebanyak 19 spesies dari 3 divisi. Spesies terbanyak didominasi oleh chlorophyta sebanyak 9 spesies 
(Tabel 1) kemudian diikuti oleh rhodophyta sebanyak 7 spesies (Tabel 2) serta phaeophyta sebanyak 3 spesies (Tabel 3).

Tabel 1. Komposisi spesies makro alga divisi chlorophyta di pulau Siko.

\begin{tabular}{c|l|l|l|l|l|l}
\hline No & \multicolumn{1}{|c|}{ Divisi } & \multicolumn{1}{c|}{ Kelas } & \multicolumn{1}{c|}{ Ordo } & \multicolumn{1}{c}{ Famili } & \multicolumn{1}{c}{ Genus } & \multicolumn{1}{c}{ Spesies } \\
\hline 1 & Chlorophyta & Chlorophyceae & Bryopsidales & Caulerpaceae & Caulerpa & sertularioides \\
\hline 2 & Chlorophyta & Chlorophyceae & Bryopsidales & Caulerpaceae & Caulerpa & serrulata \\
\hline 3 & Chlorophyta & Chlorophyceae & Bryopsidales & Caulerpaceae & Caulerpa & racemosa \\
\hline 4 & Chlorophyta & Chlorophyceae & Bryopsidales & Halimedaceae & Halimeda & macroloba \\
\hline 5 & Chlorophyta & Chlorophyceae & Bryopsidales & Halimedaceae & Halimeda & tuna \\
\hline 6 & Chlorophyta & Chlorophyceae & Bryopsidales & Halimedaceae & Halimeda & incrassata \\
\hline 7 & Chlorophyta & Chlorophyceae & Bryopsidales & Halimedaceae & Halimeda & opuntia \\
\hline 8 & Chlorophyta & Chlorophyceae & Bryopsidales & Halimedaceae & Halimeda & opuntia f. chordata \\
\hline 9 & Chlorophyta & Chlorophyceae & Cladophorales & Siphonocladaceae & Chaetomorpha & spiralis \\
\hline
\end{tabular}

Tabel 2. Komposisi spesies makro alga divisi phaeophyta di pulau Siko.

\begin{tabular}{c|c|l|l|l|l|c}
\hline No & Divisi & \multicolumn{1}{|c|}{ Kelas } & Ordo & \multicolumn{1}{|c|}{ Famili } & \multicolumn{1}{|c}{ Genus } & Spesies \\
\hline 1 & Phaeophyta & Phaeophyceae & Dictyotales & Dictyotaceae & Dictyota & dichotoma \\
\hline 2 & Phaeophyta & Phaeophyceae & Dictyotales & Dictyotaceae & Padina & minor \\
\hline 3 & Phaeophyta & Phaeophyceae & Dictyotales & Dictyotaceae & Padina & tetrastomatica \\
\hline
\end{tabular}

Tabel 3. Komposisi spesies makro alga divisi phaeophyta di pulau Siko.

\begin{tabular}{l|l|l|l|l|l|l}
\hline No & \multicolumn{1}{|c|}{ Divisi } & \multicolumn{1}{c|}{ Kelas } & \multicolumn{1}{c|}{ Ordo } & \multicolumn{1}{c}{ Famili } & \multicolumn{1}{c}{ Genus } & \multicolumn{1}{c}{ Spesies } \\
\hline 1 & Rhodophyta & Rhodophyceae & Ceramiales & Rhodomelaceae & Acanthophora & spicifera \\
\hline 2 & Rhodophyta & Rhodophyceae & Ceramiales & Rhodomelaceae & Amphiroa & foliacea \\
\hline 3 & Rhodophyta & Rhodophyceae & Ceramiales & Rhodomelaceae & Amphiroa & rigida \\
\hline 4 & Rhodophyta & Rhodophyceae & Cryptonemilales & Rhizophilidaceae & Gracilaria & edulis \\
\hline 5 & Rhodophyta & Rhodophyceae & Cryptonemilales & Rhizophilidaceae & Gracilaria & verucossa \\
\hline 6 & Rhodophyta & Rhodophyceae & Cryptonemilales & Rhizophilidaceae & Gracilaria & salicornia \\
\hline
\end{tabular}

\section{III.3. Deskripsi spesies makro alga dan habitatnya}

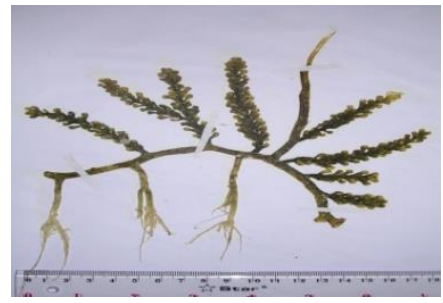

1. Caulerpa racemosa (Forsskal) J. Agardh, 1928

Pengamatan :

Menjalar secara horisontal dengan panjang stolon 12,5 $-39,8 \mathrm{~cm}$ dan diameter $0,2-0,4 \mathrm{~mm}$. terdapat cabang ramuli yang menyerupai buah berjumlah $2-5$ yang berbentuk bulat bertangkai seperti buah anggur. Jumlah buah 4-16, berukuran besar, tinggi ramuli dapat mencapai 1,6-6,1 cm, lebar ramuli 0,1-0,2 cm, dan jarak antar ramuli 2,4-5,1 cm. Melekat dengan holdfast rhizoid berjumlah 4-8, panjang holdfast 1,2-3,6 cm. Alga ini dimakan oleh masyarakat setempat setelah dimasak dengan santan. Habitat Hidup pada substrat batu karang dan pasir berbatu di bagian atas subtidal. 


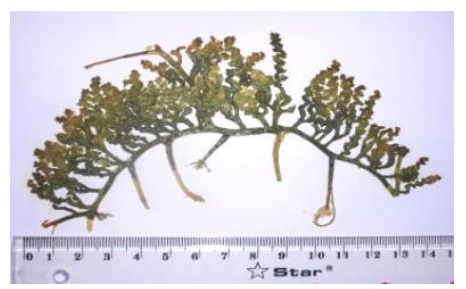

2. Caulerpa serrulata (Forsskal) J. Agardh, 1937

Pengamatan :

Thallus berwarna hijau tua dan kekuningan di bagian apeks, dengan stolon menjalar secara horisontal. Percabangan muncul dari ramulus terete, blade memanjang berbentuk pipih dengan bagian tepi bergerigi, percabangan tunggal tetapi kadang-kadang dichotomous berjumlah 2-4. Tinggi ramulus 3,5 -5,1 cm berjumlah 8-9 dengan lebar rumulus $0,3-0,8 \mathrm{~cm}$, tinggi stipe $0,2-0,4 \mathrm{~cm}$, rhizoid terletak pada bagian bawah stolon dengan panjang 14,8-38 cm dan diameter 0,2 -0,3 mm berjumlah 5-11. Habitat Daerah pasir bercampur karang, pasir bercampur lumpur.

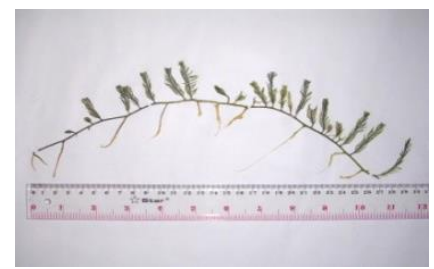

3.Caulerpa sertularioides (S. Gmelin) Howe, 1905

Pengamatan :

Thallus dengan stolon padat dan menjalar dengan phylarizoid yang terdapat di bawahnya dengan panjang 8,3 $-21,4 \mathrm{~cm}$, diameter stolon $0,2-0,3 \mathrm{~mm}$. Jumlah ramuli 714 , terdapat cabang-cabang yang tegak dengan blade berbentuk lengkungan panjang dan ramping, tinggi thallus mencapai $6-6,8 \mathrm{~cm}$, blade tersusun secara pinnate distichous dengan panjang 0,4-1,1 cm. Habitat Substrat berpasir dan pasir bercampur lumpur.

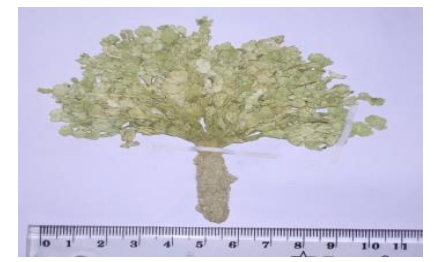

4. Halimeda incrassata (Ellis) Lamouroux, 1816

Pengamatan :

Thallus tegak dengan tinggi $8-13,4 \mathrm{~cm}$ dan diameter segmen 0,4-0,8 $\mathrm{m}$, agak rimbun, di alam berwarna hijau muda dan krem ketika sudah kering. Segmen berjumlah 28-68, kaku, agak keras, berkapur, pertumbuhannya melebar seperti kipas tampak rata pada satu bidang, segmen pangkal tampak seperti silinder dan tebal, sangat kaku, kelihatan menyatu dengan lebar $6,4 \mathrm{~cm}$ berwarna hijau kecoklatan. Tinggi dari holdfast ke percabangan pertama $0,4-1,8 \mathrm{~cm}$. Segmen bagian tengah ke atas berbentuk seperti segitiga terbalik, kadang sedikit oval atau seperti silinder pipih, pada umumnya bertekuk tiga, holdfast seperti umbi dengan panjang 0,7-1,4 cm. Habitat Substrat berpasir dan pasir bercampur lumpur. 


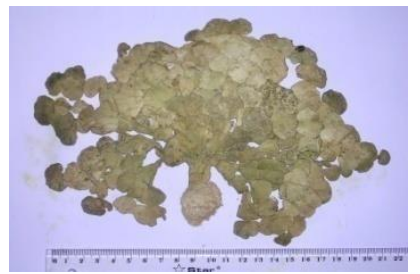

\section{Halimeda macroloba Decaisne, 1814}

Pengamatan :

Thallus rimbun dengan tinggi total mencapai $11,6-25,3 \mathrm{~cm}$, tinggi dari pangkal sampai ke percabangan pertama 10,3-22,2 cm. Blade sangat kaku, berkapur dengan bentuk seperti gada, lebar 1,3-2,6 $\mathrm{cm}$ dan tinggi 1,5 - 3,1 cm. Mempunyai jumlah percabangan 3-4, tersusun tumpang tindih. Holdfast seperti umbi yang memanjang (bulbous) sekitar 1,1-3,2 cm. Thallus berwarna hijau pada saat masih segar dan berwarna kuning kehijauan pada saat kering. Habitat Substrat berbatu, karang berpasir, dan bercampur lumpur.

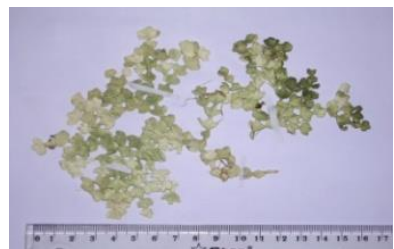

6. Halimeda opuntia (Linneaus) forma triloba Lamouroux, 1816

\section{Pengamatan :}

Thallus tegak, bersegmen dengan percabangan tidak teratur. Segmen membentuk segitiga dan pada ujungnya muncul segmen-segmen baru. Tinggi thallus 12,8-22,6 cm. Jumlah segmen 208-1121. Alat pelekat berupa filamen yang keluar dari segmen basal yang mencengkram substrat, blade berkapur, sangat kaku, bentuknya bertekuk tiga, lebar blade 0,2-0,9 cm, susunannya tumpang tindih, tidak teratur dan tidak terletak pada satu percabangan tidak beraturan sehingga thallus terletak tidak pada satu bidang. Habitat Substrat berpasir dan karang pada daerah intertidal hingga subtidal.

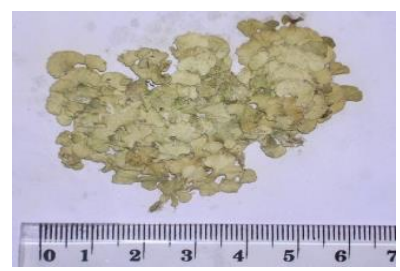

7. Halimeda opuntia forma chordata (Linneaus) Lamouroux

\section{Pengamatan :}

Thallus tegak, bersegmen dengan percabangan trichotomous. Segmen membentuk segitiga dan pada ujungnya muncul segmen-segmen baru. Tinggi thallus $8-15,1 \mathrm{~cm}$. dengan diameter $0,4-0,8 \mathrm{~cm}$. Alat pelekat berupa filamen yang keluar dari segmen basal yang mencengkram substrat, blade berkapur, sangat kaku, bentuknya bertekuk tiga, lebar blade 0,2-0,5 cm, jumlah segmen 129-724, susunannya tumpang tindih, tidak teratur dan tidak terletak pada satu percabangan tidak beraturan sehingga thallus terletak tidak pada satu bidang. Habitat Substrat berpasir dan karang pada daerah intertidal hingga subtidal. 


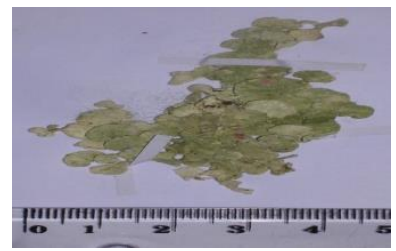

8. Halimeda tuna (Ellis dan Solander) Lamouroux, 1816

Pengamatan :

Tinggi thallus 7,3-10,4 cm dan berjumlah 19-43, diameter segmen 0,7-2,1 cm, segmen lemas dan segmen bagian tengah cenderung lebih besar daripada bagian pangkal dan apeks pada umumnya berbentuk oval. Lebar mencapai 4-4,9 cm. Blade tampak langsung berlekatan kecuali pada bagian percabangan. Percabangannya trichotomous dan kadang tumpang tindih. Memiliki alat pelekat berupa rhizoid yang berkumpul seperti cakram dengan panjang 0,1-1,6 cm. Habitat Substrat berpasir, karang mati dan berbatu di daerah intertidal.

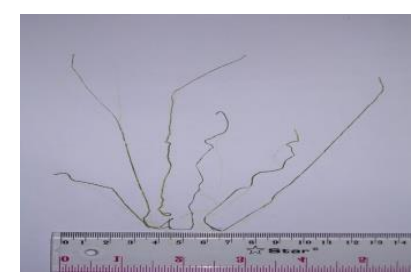

\section{Chaetomorpha spiralis Okamura, 1903}

Pengamatan :

Thallus berupa benang yang berbentuk spiral, berwarna hijau tua. Hidup secara eksotik dengan melingkar pada tumbuhan lain seperti lamun serta mengapung pada permukaan air. Tinggi thallus sekitar $42-58 \mathrm{~cm}$ dan diameter $0,1 \mathrm{~mm}$.

Habitat: Substrat berpasir dan sebagai efipit pada lamun.

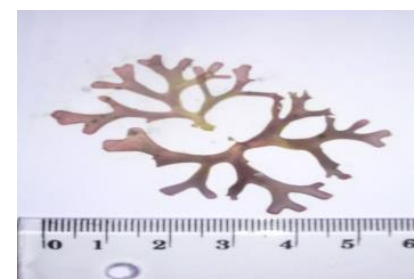

10. Dictyota dichotoma (Hudson) Lamouroux, 1809

Pengamatan :

Thallus pipih seperti pita dengan tinggi thallus 4,7-5,4 cm, lebar thallus $0,3-0,4$ $\mathrm{cm}$. Pinggiran thallus rata, percabangan dichotomous dengan bagian apeks yang sedikit membulat. Mempunyai holdfast discoid dengan warna thallus coklat tua dan pada bagian ujung thallus membelah dengan panjang yang sama. Habitat Menempel pada substrat berbatu, pasir dan karang mati. 


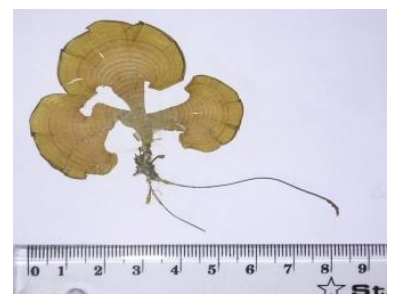

11. Padina minor Yamada, 1925

Pengamatan :

Thallus relatif kecil dan tebal, lamina berbentuk seperti kipas. Tinggi thallus 5,3$9,3 \mathrm{~cm}$, berwarna coklat kekuningan dan terdiri dari beberapa flabellate lobes lebarnya 4,3-9,8 cm. Memiliki garis konsentrik ganda berjumlah 6-11 yang terbentuk dari pangkal blade hingga memenuhi permukaan blade. Thallus tumbuh membentuk koloni dengan holdfast rhizoid dengan panjang $8 \mathrm{~cm}$. Habitat Substrat berpasir, karang batu pada daerah intertidal.

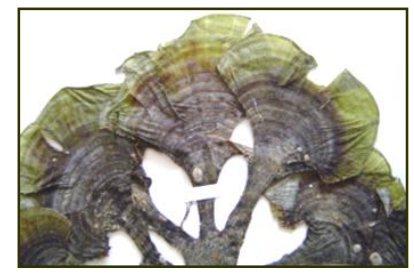

12. Padina tetrastromatica Hauck, 1887

Pengamatan :

Thallus membentuk lamina seperti kipas, tingginya 9,9-14,8 cm, berwarna coklat kehijauan. Blade melebar berdiameter 9,1-12,9 cm, tipis dan licin. Pada bagian apeks terdapat beberapa flabellate lobes lebarnya $0,4-1,1 \mathrm{~cm}$. Tinggi thallus dari holdfast ke percabangan pertama 1,2 cm, holdfast rhizoid kecil. Jumlah garis konsentrik 18-29. Habitat Karang, pasir di daerah intertidal.

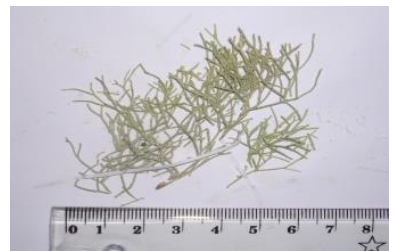

13. Amphiroa foliacea Lamouroux, 1824

Pengamatan :

Thallus rimbun dengan panjang 4,2-5,3 dan tinggi 2,4-3,1 cm, berwarna putih kekuningan, mempunyai segmen bersayap penuh kapur. Percabangan secara dichotomous dengan panjang 0,6-0,8, irregular, holdfast discoid dekat stipe. Konseptakel terdapat di bagian basal segmen hingga pertengahan thallus. Habitat Di celah-celah bebatuan, karang batu. 


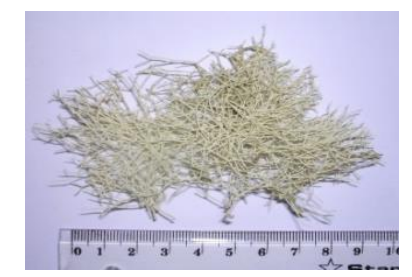

\section{Amphiroa rigida Lamouroux, 1816}

Pengamatan :

Thallus silindris tegak dengan tinggi 4,3-5,2 cm, membentuk koloni warna merah dengan holdfast berupa cakram kecil, percabangan tidak beraturan, thallus I berkapur. Tinggi thallus 3,2-5,8 $\mathrm{cm}$ dan lebar $0,9-1,1 \mathrm{~mm}$. Terdapat genikula yang menghubungkan segmen-segmen intergenikula. Habitat Substrat rataan terumbu.

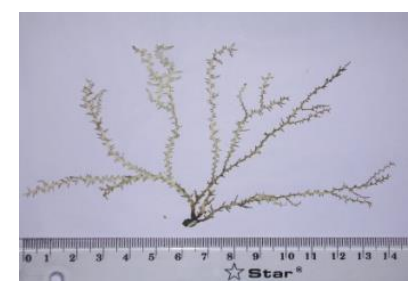

15. Acanthophora spicifera (Vahl) Borgesen, 1910

Pengamatan :

Thallus tegak, berwarna coklat tua, tinggi thallus $8,3-14,5 \mathrm{~cm}$ dan diameter 0,2 $\mathrm{cm}$, tinggi dari holdfast ke percabangan pertama $0,8 \mathrm{~cm}$ dengan jumlah cabang 5-12. Stipe berbentuk silindris, memiliki duri-duri pendek di sekitar thallus. Bentuk percabangannya tidak beraturan pada bagian apeks thallus agak meruncing.

Habitat substrat berbatu atau substrat keras lainnya.

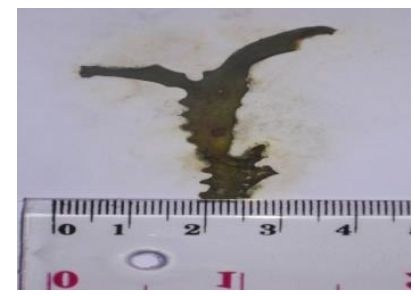

16. Eucheuma gelatinae J. Agardh, 1847

Pengamatan :

Thallus tebal, agak melebar dan berbentuk silindris, tidak berlendir, tinggi 10,3$13,3 \mathrm{~cm}$ dengan diameter 1,3-1,6 cm. Terdapat cabang sekunder dengan ujung yang tajam. Ujung apeks kadang bercabang sekunder. Sepanjang thallus terdapat seperti duriduri yang tajam dan terletak saling berhadapan. Cabang utama berbentuk rata, berwarna hijau muda saat masih segar dan hijau kecoklatan setelah kering. Bentuk percabangan tidak beraturan, melekat dengan holdfast discoid. Habitat Hidup pada substrat berpasir dan pasir berbatu. 


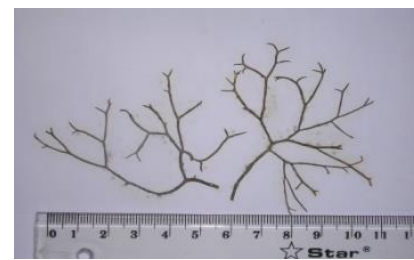

17. Gracilaria edulis (S. Gmelin) P. Silva 1952

Pengamatan :

Thallus berbentuk silindris, tinggi 4,5-15,3 cm dengan diameter 0,1-0,2 $\mathrm{mm}$. Bagian holdfast berbentuk discoid kecil. Bercabang dichotomous, kadang dijumpai tidak beraturan, pada bagian apeks biasanya mengecil dan melengkung waktu kering. Thallus berwarna coklat kehijauan di alam dan coklat tua saat kering. Habitat Substrat pasir berbatu, lumpur di daerah intertidal.

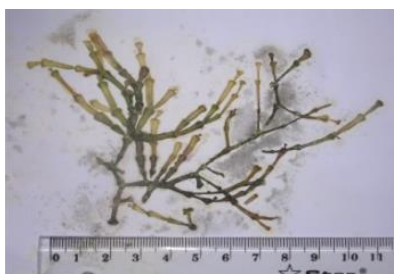

18. Gracilaria salicornia (C. Agardh) Dawson, 1954

Pengamatan :

Thallus berbentuk silindris, licin, bersegmen-segmen membentuk rumpun yang lebat, tinggi mencapai 5,3-14,4 $\mathrm{cm}$ dengan diameter $0,3-0,4 \mathrm{~mm}$, bagian holdfast berbentuk discoid. Bentuk percabangan dichotomus tetapi kadang tidak beraturan, umumnya timbul pada setiap bagian antar segmen. Berwarna hijau kekuningkuningan sampai oranye pada perairan jernih tapi pada perairan keruh berwarna coklat tua. Habitat Substrat pasir, lumpur pada daerah intertidal.

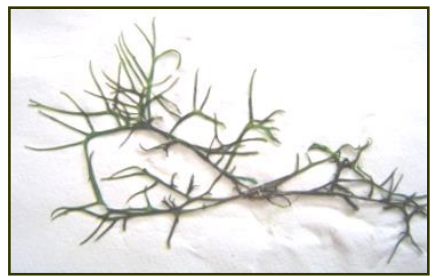

19. Gracilaria verrucosa (Hudson) Papenfuss, 1950

Pengamatan :

Thallus silindris, licin, berwarna kuning-coklat dengan tinggi 5,8-8,6 cm, diameter thallus $0,1-0,2 \mathrm{~mm}$. Percabangan berselang-selang tidak beraturan, kadang-kadang berulang-ulang memusat ke bagian pangkal. Cabang-cabang lateral memanjang menyerupai rambut, tinggi thallus total mencapai $12 \mathrm{~cm}$.

Habitat Substrat karang mati dan berpasir pada daerah intertidal.

\section{Kesimpulan}

Berdasarakan identifikasi komposisi jenis pada stasiun penelitian di perairan pantai Siko ditemukan sebanyak 19 spesies dari 3 divisi. Diantara jumlah spesies tersebut terdapat salah satu spesies yang memiliki diameter tinggi thallus yang cukup besar yaitu spesies halimeda macroloba dengan tinggi thallus mencapai $25,3 \mathrm{~cm}$. Berdasarkan hasil pengukuran thallus tersebut dapat disimpulkan bahwa besarnya diameter thallus 
disebabkan karena diperairan kepulauan guraici merupakan perairan yang berhadapan langsung dengan laut pasifik, sehingga daerah ini menerima nutrient (unsur hara) yang masuk terbawa arus ke perairan ini.

Selain itu berdasarkan tipe substrat yang dimiliki oleh perairan disekitar lokasi pulau Siko tersebut yaitu substrat pasir, pasir berlumpur, berkarang dan berbatu yang merupakan tempat ideal bagi pertumbuhan alga, terutama spesies yang ditemukan dalam penelitian ini. Perairan ini pula mempunyai topografi pantai yang agak landai dengan perairan relatif terlindung yang merupakan suatu ciri tempat yang baik bagi kehidupan alga terutama pada jenis-jenis yang ditemukan di perairan ini.

\section{Daftar Pustaka}

Calumpong, H.P. dan E.G. Menez. 1997. Field Guide to the Common Mangroves: Seagrasses and Algae of the Philippines. Bookmark, Inc, 264-A Pablo Ocampo Sr. Ave. Makati City, Philippines. 197 hal.

Gerung, G. S. 2001a. Biodiversitas Alga Laut (Rumput Laut). Pidato Ilmiah. Fakultas Perikanan dan Ilmu Kelautan. Universitas Sam Ratulangi Manado.

Lobban, Ch. S. dan P. J. Harrison. 1994. Seaweed Ecology and Physiology. Cambridge Univ. Press. 366 hal.

Luning, K. 1990. Seaweeds : Their Environment, Biogeography and Ecophysiology. John Wiley and Sons, Inc. 527 hal.

Nontji, A. 1993. Laut Nusantara. Suatu Pendekatan Ekologis. Penerbit Djambatan. 367 hal.

Sumich, J. L. 1992. Introduction to the Biology of Marine Life. Wmc. Brown Publisher. USA.

Trainor, F. G. 1978. Introduction to the Biology of Marine Life. Wm. C. Brown Company Publisher IOWA.

Trono, G. C. 1997. Field Guide and Atlas of the Seaweed Resources of the Philippines. Boolmark, Inc. Makaty City. 306 hal. 